\title{
T-cell epitope polymorphisms of the Plasmodium falciparum circumsporozoite protein among field isolates from Sierra Leone: age-dependent haplotype distribution? Amadu Jalloh*1,2, Muctarr Jalloh ${ }^{3}$ and Hiroyuki Matsuoka ${ }^{1}$
}

\author{
Address: ${ }^{1}$ Division of Medical Zoology, Department of Infection and Immunity, Jichi Medical University, Yakushiji 3311-1, Shimotsuke, Tochigi \\ 329-0498, Japan, ${ }^{2}$ College of Medicine and Allied Health Sciences, University of Sierra Leone, Private Mail Bag, Freetown, Sierra Leone and \\ ${ }^{3}$ Princess Christian Maternity and Children's Hospital, Freetown, Sierra Leone \\ Email: Amadu Jalloh* - alphmadu@yahoo.com; Muctarr Jalloh - jallohmuctarr@yahoo.com; Hiroyuki Matsuoka - hiroyuki@jichi.ac.jp \\ * Corresponding author
}

Published: 5 June 2009

Malaria Journal 2009, 8:120 doi:10.1 186/1475-2875-8-120
Received: 30 January 2009

Accepted: 5 June 2009

This article is available from: http://www.malariajournal.com/content/8/I//20

(C) 2009 Jalloh et al; licensee BioMed Central Ltd.

This is an Open Access article distributed under the terms of the Creative Commons Attribution License (http://creativecommons.org/licenses/by/2.0), which permits unrestricted use, distribution, and reproduction in any medium, provided the original work is properly cited.

\begin{abstract}
Background: In the context of the development of a successful malaria vaccine, understanding the polymorphisms exhibited by malaria antigens in natural parasite populations is crucial for proper vaccine design. Recent observations have indicated that sequence polymorphisms in the C-terminal T-cell epitopes of the Plasmodium falciparum circumsporozoite protein (Pfcsp) are rather low and apparently stable in low endemic areas. This study sought to assess the pattern in a malaria endemic setting in Africa, using samples from Freetown, Sierra Leone.
\end{abstract}

Methods: Filter-paper blood samples were collected from subjects at a teaching hospital in Freetown during September-October 2006 and in April-May 2007. The C-terminal portion of the Pfcsp gene spanning the Th2R and Th3R epitopes was amplified and directly sequenced; sequences were analysed with subject parameters and polymorphism patterns in Freetown were compared to that in other malaria endemic areas.

Results and Discussion: Overall, the genetic diversity in Freetown was high. From a total of 99 sequences, 42 haplotypes were identified with at least three accounting for 44.4\% (44/99): the 3D7type (19.2\%), a novel type, P-OI (I7.2\%), and EI2 (8.I\%). Interestingly, all were unique to the African sub-region and there appeared to be predilection for certain haplotypes to distribute in certain age-groups: the 3D7 type was detected mainly in hospitalized children under 15 years of age, while the P-0I type was common in adult antenatal females (Pearson Chi-square $=48.750$, degrees of freedom $=34, P=0.049$ ). In contrast, the single-haplotype predominance (proportion $>50 \%$ ) pattern previously identified in Asia was not detected in Freetown.

Conclusion: Haplotype distribution of the T-cell epitopes of Pfcsp in Freetown appeared to vary with age in the study population, and the polymorphism patterns were similar to that observed in neighbouring Gambia, but differed significantly at the sequence level from that observed in Asia. The findings further emphasize the role of local factors in generating polymorphisms in the T-cell epitopes of the $P$. falciparum circumsporozoite protein. 


\section{Background}

Every year malaria kills more than a million people worldwide [1] and the need for an effective vaccine to boost control efforts cannot be over-emphasized. In the context of the development of a successful malaria vaccine, a major potential obstacle is the issue of genetic polymorphisms exhibited by malaria antigens. While an understanding of these polymorphisms in natural plasmodium populations is not only crucial for proper vaccine design, deployment and evaluation, such data may also provide invaluable insights into host-parasite interaction(s). The Plasmodium falciparum circumsporozoite protein (Pf-CSP) is the most abundant protein on the sporozoite's surface and has a sequence comprising a central repeat that is flanked by polymorphic N-terminal and C-terminal nonrepeat regions. The Pf-CSP antigen is the primary component of the RTS,S [2], which is one of the leading malaria vaccine candidates, and the only one to have shown moderate, but promising, results during Phase II trials in adults in The Gambia [3] and children in Mozambique [4]. Plans for Phase III trials are currently underway in 10 African nations [5]. Although field data on malaria antigen polymorphisms generally have been rather scanty, there is now an improving trend partly due to increased training of and collaboration with researchers in endemic nations.

With regards to the Pfcsp gene, two distinct polymorphisms have been described: polymorphism in the number of NANP repeats and single nucleotide polymorphisms (SNPs) in non-repeat regions. Although polymorphisms in the number of NANP repeats can be extensive even in low endemic areas [6], it has been documented that SNPs in the non-repeat regions (Th2R/Th3R epitopes) in such settings, e.g. Southeast Asia, are stable for an observation period of at least five years in Vietnam [7], or 10 years in Thailand [8]. Moreover, the overall scenario suggests that Asian parasites (with respect to the Th2R/Th3R regions) are somewhat "clonal", with one majority sequence predominating, probably reflecting distinct differences between parasites from Asia (lower endemicity) and Africa (higher endemicity). However, samples examined from Africa at the population level tended to be relatively small and with variation in sampling time-points. These findings prompted the investigation of the diversity of Pfcsp gene in a typical African malaria-endemic setting in Sierra Leone. With no previous data on this important topic in the country, the main aim herein was to collect baseline sequence data and to characterize sequence polymorphisms of the T-cell epitopes of Pf-CSP among field isolates distributing in the capital, Freetown, with an ultimate aim of acquiring insight into host-parasite interaction(s). In addition, this study examined whether there was any significant difference in polymorphism patterns between African and Asian parasites. Results confirmed marked sequence diversity of African isolates as compared to Asia, with at least three major haplotypes in Freetown. Moreover, haplotype distribution in this endemic area appeared to vary with age, and presumably immunity status. Implications of findings are discussed with regards to malaria vaccine design and local malaria epidemiology.

\section{Methods \\ Study area}

This study was conducted at the Princess Christian Maternity and Children's Hospital (PCMH), as part of a study on G6PD deficiency polymorphisms, which has been described in [9]. The PCMH is located in the East End of Freetown, where it is surrounded by overcrowded residential and market areas. As the name implies, the hospital not only plays a vital role in maternity medicine, but also serves as one of the main national paediatric centers in the country. Malaria transmission in Freetown is perennial with apparent fluctuations in intensity during the rainy (May-October) and dry (November-April) seasons. Although there have been no recent malaria-related entomologic studies in the capital, earlier studies have identified Anopheles gambiae, Anopheles funestus, Anopheles melas, and Anopheles nili as efficient local malaria vectors, with $P$. falciparum being the dominant parasite species (reviewed in [10]). Previous research [10] also identified the capital as fluctuating between that of a meso- and hyper-endemic area, but studies are urgently required to properly assess the current situation. Despite the long history of malaria control activities in Sierra Leone, the disease is still a major public health problem and accounts for about $40 \%$ of outpatient consultations in the country. Presumptive diagnosis followed by self-treatment is not uncommon, and is thought to contribute greatly to the widespread drug resistance recently documented in the country, warranting a recent shift in national malaria treatment policy [11].

\section{Sample collection}

Hospital-based surveys were conducted in mid-September to mid-October 2006 and in mid-April to mid-May 2007. Participants in this study comprised two main groups of individuals residing in Freetown: (i) symptomatic children visiting and/or admitted at the PCMH, as well as (ii) antenatal out-patients visiting the PCMH microbiology laboratory for routine blood tests (e.g. malaria microscopy, differential cell count, haemoglobin levels etc.). Patients were introduced to the study and those consenting were screened for malaria via microscopy, and filter paper blood samples were collected for each subject. Filter paper blood spots were air-dried, sealed in tiny plastic bags and stored at room temperature $\left(25-31^{\circ} \mathrm{C}\right)$, until later molecular analysis at Jichi Medical University, Tochigi, Japan. Prior to blood donation, subjects were interviewed and basic demographic information for each 
participant were recorded including age, sex, ethnicity, and whether they were admitted at the hospital (i.e. inpatients) or only visiting (out-patients). Falciparum parasitaemia (parasite density) was determined for each subject by local microscopists, but due to technical limitations encountered in the field parasite density data was not utilized further.

\section{DNA extraction and sequencing}

Genomic DNA was extracted from randomly selected filter paper blood samples using the GFX kit (GE Healthcare, $\mathrm{UK})$, regardless of microscopy results. The C-terminal portion spanning the T-cell epitope regions of the gene of $P$. falciparum csp was amplified by a semi-nested PCR using primers and cycle conditions described in [12]. In brief, the first PCR used primers 5'-aatcaaggtaatggacaagg-3' (CSo101) and 5'-ctaattaaggaacaagaagg-3 (CSo102); and 1 $\mu$ l of the PCR product was used in a second round PCR using primers CSo101 and a second reverse primer, 5'ggaacaagaaggataatacc-3' (CSo104) in a $20 \mu \mathrm{l}$ reaction mixture. Amplified gene fragments were resolved on $2 \%$ agarose gels following electrophoresis and visualized by ultraviolet (UV) light. The fragments of positive samples were excised using FUNA Gel pipette tips (Funakoshi, Tokyo, Japan), and diluted with 40-100 $\mu$ l deionized distilled water depending on band intensity. Five microlitres of diluted DNA was used as template for cycle sequencing in a $10 \mu \mathrm{l}$ reaction and the reverse primer was used to read the sequences for each fragment on an ABI 310 Genetic Analyzer. In principle, sequences were read once per sample using the second reverse primer (CSo104) but when a new mutation was encountered or when two electrophoregram peaks overlapped at a known mutation site, sequencing was repeated with another independent sample using the forward primer (CSo101).

\section{Sequence alignment and statistical analyses}

Sequences were aligned using MEGA4 software [13] and manually edited, with the sequence of the 7G8 strain from Brazil [14] serving as reference. Each csp sequence was treated as an independent entity, coded and statistical analysis was conducted using the SPSS 10.0 software for Windows. The 2-sided Pearson Chi-square test of independence for categorical variables was used to compare the respective frequencies of haplotypes with regards to subject parameters including age, ethnicity, sex, and "status" (i.e. whether hospitalized or not), as well as time of sample collection. This was done in an attempt to examine the hypothesis whether haplotype distribution was associated with age (and presumably immunity status) or any of the other parameters described above. Statistical significance was set at the $5 \%$ level $(P=0.05)$.

In an effort to examine geographical diversity patterns with other parasite populations, the C-terminal portion of recently published Pfcsp sequences from Vietnam [7] ( $n=$ $142)$, from Iran $(n=90)$ described in [15], and from one cohort $(n=44)$ of field isolates from neighbouring Gambia [16] were analysed. Commonly used intra-population and inter-population genetic parameters were estimated using DnaSP 4.5 software [17] and compared between African (The Gambia and Sierra Leone) and Asian sequences (Vietnam and Iran). Parameters investigated include nucleotide diversity, pi $(\pi)[18]$, which is the average number of substitutions between any two sequences, and haplotype (gene) diversity values [18]. In addition, the Wright's Fixation statistic $\left(\mathrm{F}_{\mathrm{ST}}\right)$ [19], which measures genetic differentiation between sub-populations, and Nei's parameters [18] including the average number of nucleotide differences per site (Dxy), net nucleotide substitution per site (Da), and average proportions of nucleotide substitutions per site (Kxy) between populations, were also estimated.

This study was approved by the Ethical Committees of the PCMH, University of Sierra Leone and Jichi Medical University, Tochigi, Japan, and the partial Pfcsp sequences obtained herein have been submitted to GenBank with accession numbers GQ119637-GQ119678.

\section{Results \\ Overview of data}

Table 1 describes the demographic characteristics of all study subjects in the PCMH 2006 study-group who provided blood samples, as well as the number of DNA samples successfully sequenced and analysed. For analytic purposes, subjects from this PCMH 2006 study-group were categorised into three main age groups: (i) below five years of age, (ii) 5-14 years of age, and (iii) 15 years and older. Of 164 filter paper blood samples, DNA was isolated from 102 samples (i.e. isolates) of which 81 showed bands (positive samples) following PCR amplification for the target Pfcsp gene fragment of 321 base pairs (bp), and

Table I: Summary characteristics of the PCMH 2006 study subjects $(\mathbf{N}=164)$

\begin{tabular}{|c|c|c|c|c|c|}
\hline \multirow[b]{2}{*}{ Sex } & \multicolumn{2}{|c|}{ Age (in years) } & \multicolumn{2}{|c|}{ Number of subjects } & \multirow{2}{*}{$\begin{array}{c}\text { Total }^{\mathrm{a}} \\
\mathrm{N}(\mathrm{n})\end{array}$} \\
\hline & Group & Mean \pm SD & Inpatient & Outpatient & \\
\hline \multirow[t]{3}{*}{ Female } & $<5 \mathrm{yr}$ & $2.1 \pm 1.4$ & $16(4)$ & $14(5)$ & $30(9)$ \\
\hline & $5-14 \mathrm{yr}$ & $8.5 \pm 3.0$ & $3(I)$ & $14(3)$ & $17(4)$ \\
\hline & $\geq 15 \mathrm{yr}$ & $25.6 \pm 6.7$ & $3(0)$ & $67(18)$ & $70(18)$ \\
\hline Subtotal & & $17.1 \pm 11.9$ & $22(5)$ & $95(26)$ & $117(3 \mid)$ \\
\hline \multirow[t]{3}{*}{ Male } & $<5 \mathrm{yr}$ & $1.8 \pm 1.3$ & $9(7)$ & $14(14)$ & $23(21)$ \\
\hline & $5-14 \mathrm{yr}$ & $8.5 \pm 2.8$ & $8(6)$ & $8(8)$ & $16(14)$ \\
\hline & $\geq 15 \mathrm{yr}$ & $26.5 \pm 7.5$ & $0(0)$ & $8(6)$ & $8(6)$ \\
\hline Subtotal & & $8.3 \pm 9.5$ & $17(13)$ & $30(28)$ & $47(4 I)$ \\
\hline
\end{tabular}

a $\mathrm{N}$ represent the total number of blood sample donors and numbers in parentheses indicate subjects whose DNA samples were successfully sequenced and analyzed $(n=72)$ 
these were successfully sequenced. Sixty-six sequences were of clear electrophoregram peaks showing no or low $(<1 / 3)$ background overlap of the dominant peak. These were referred to as "single dominant" sequences and coded as "single-clone" infections. Six samples revealed sequences with electrophoregram peaks overlapping at one known mutation site for which both possible amino acid sequences were deduced from the nucleotide sequence (total $n=6 \times 2$ ). Nine samples showed chromatogram peak overlap at two or more known mutation sites (termed "mixed-clone" infections), and were omitted in the analysis presented here.

Among blood samples collected during the April-May 2007 survey, an additional set collected from the Thirty Fourth Military Hospital (M-34) at Wilberforce (located in the Western Area of Freetown, about $6 \mathrm{Km}$ from the PCMH) were also analysed. Of these 2007 samples, 12 of $47(25.5 \%)$ from the PCMH and nine of $30(30.0 \%)$ from M-34 amplified and were sequenced, and all revealed "single-dominant" sequences (Figure 1). There was a significant difference (Chi-square $=3.84$, degree of freedom, d.f. $=1, P<0.0001)$ in the number of PCR-positive samples between isolates collected in September-October 2006 i.e. during the rainy season $(81 / 102$ or $79.4 \%)$ and in April-May 2007 i.e. the dry season (21/77 or 27.2\%).

\section{Haplotype distribution with age, sex and other parameters} Pooling the data and analysis of the whole set of 99 C-terminal csp sequences (including the six double-clone infections) from Freetown identified a total of 42 unique haplotypes for which the respective proportions are depicted in Figure 1. Three major haplotypes were detected: the 3D7-type (19.2\%) which is identical to the RTS, $S$ vaccine sequence, a previously undescribed haplotype, P-01 (17.2\%), and E-12 (8.1\%) a sequence that has been reported from neighbouring Gambia. A majority of the remaining haplotypes comprised mostly minority alleles and almost all were unique to the West African subregion at the nucleotide level. Consistent with previous studies, almost all mutations observed (except for haplotype P-17) were non-synonymous, and clustered in the Tcell epitope regions (Th2R, Th3R) of the gene, although a few sequences had mutations in the region preceding the Th2R (labeled X in Figure 1). Moreover, there was an Arg $>$ Gly substitution (haplotype P-10 in Figure 1) in the highly conserved region II i.e. a region sandwiched between the Th2R and Th3R, which has been implicated in hepatocyte binding [20]. Interestingly, most of the observed haplotypes usually differed from one another by one non-silent point mutation in the whole C-terminal region. For example, the P-10 haplotype differed from the 3D7 sequence only by the amino residue substitution at position 360 in Figure 1, while the P-01 isolate that dominated in antenatal out-patients differed from the P-30 isolate only by the $\mathrm{R}>\mathrm{T}$ substitution at residue position 337. Haplotypes E12 and Cam 3006 differed by one mutation in Th2R, whereas 3D7 and P-03 differed by a mutation in the Th3R. A similar trend was observed for other haplotypes, tempting the speculation that some form of recombination events might be occurring in these C-terminal T-cell epitope regions of CSP in natural parasite populations.

Preliminary analysis for the whole set of 99 sequences revealed a non-significant (Pearson Chi-square value of 93.219, degrees of freedom $=82, P=0.187$ ), yet unexpected haplotype distribution pattern with respect to age. As shown in Figure 2, the 3D7 and a previously undescribed haplotype (P-01) appeared to predominate in different age groups, in which the former was associated with mainly children under 15 years and the latter with adult women. Subsequent sub-group analysis of the 2006 $\mathrm{PCMH}$ data (using all sequences including single as well as the six double-clone infections) by age, sex, ethnicity and patient status (i.e. in-patient or out-patient) revealed a significant, albeit weak, association only for the outpatient females (Pearson Chi-square value of 48.750 , d.f. $=34, P=0.049)$, who were mainly pregnant women visiting for regular antenatal follow-up. However, repeating the analysis with one sequence per isolate (i.e. using a randomly selected sequence from the six double-clone infected samples) reduced the p-value slightly (Pearson Chi-square value of 46.944 , d.f. $32, P=0.043$ ). The availability of fewer sequences in other sub-groups precluded further comprehensive analysis with respect to sampling time and place. Nonetheless, it appears that, in this African endemic setting, haplotype frequencies are likely to vary with time (e.g. season), as demonstrated between samples collected in 2006 (rainy season) and 2007 (dry season) in Figure 1, as well as by the proportion of PCRpositive samples in 2006 i.e. $79.4 \%(81 / 102)$ versus $27.3 \%(21 / 77)$ in 2007.

\section{Geographical distribution of csp haplotypes}

Spatial polymorphism patterns were examined by comparing recently published sympatric (of parasites from the same locality at a given time) csp sequences obtained from hospital-based surveys in different countries $[7,15,16]$. These data were acquired through direct sequencing of isolates, allowing appropriate comparison to data presented here, and only the region (207 bp) spanning the Th2R and Th3R epitopes was used (i.e. spanning amino acid positions $326-394)$. Of 375 sequences 126 (33.6\%) were of the predominant haplotype i.e. the Th2R*5/ Th3R*1 $[7,15,16]$ unique to Asia (Vietnam: $75 / 142$ or $52.8 \%$ and Iran: $51 / 90$ or $56.7 \%$ ), but was not found in The Gambia nor in Sierra Leone (Additional File 1). Similarly, other common haplotypes in West Africa (3D7, P01, E12) were not detected in Vietnam or in Iran, while 


\begin{tabular}{|c|c|c|c|c|c|c|c|}
\hline & & acid & nce & & & & \\
\hline & $\mathbf{X}$ & Th2R epitope & Th3R epitope & & & & \\
\hline Haplotype & $\underline{308-317}$ & $\underline{326-342}$ & $\underline{356-378}$ & РCMH & PCMH & M-34 & To \\
\hline $7 \mathrm{G} 8$ & VDENANANNA & PSDKHIEQYLKK IKNS I & GI QVRI KP GSANKPK DELD YEND & $\underline{2006}$ & $\underline{2007}$ & $\underline{2007}$ & $\underline{\text { Cour }}$ \\
\hline Asia-type* & $\ldots \ldots \ldots$ & $\ldots \ldots \ldots \ldots{ } . \mathrm{L}$ & $\ldots \ldots \ldots \ldots \ldots \ldots \ldots$ & & & & \\
\hline 3D7 & $\ldots \ldots s$ & $\ldots \ldots K E \ldots N \ldots Q \ldots L$ & $\ldots \ldots \ldots \ldots \ldots \ldots$ А. & 18 & & 1 & \\
\hline B01/7G8 & $\ldots \ldots \ldots$ & $\ldots \ldots \ldots \ldots$ & $\ldots \ldots \ldots \ldots \ldots \ldots$ & & 2 & 1 & \\
\hline Cam1001 &.$N \ldots \ldots$ & $\ldots \ldots K \ldots E \cdot Q \ldots L$ & $\ldots \ldots \ldots$. . . . . . . & & 1 & & \\
\hline Cam1028 & $\ldots \ldots \ldots$ & $\ldots Q \ldots K \ldots$ T...L & $\ldots \ldots \ldots \ldots \ldots$. & 2 & & & \\
\hline Cam1051 & $\ldots \ldots \ldots$ & $\ldots Q \ldots K \ldots N \ldots L L$ & $\ldots \ldots \ldots \ldots$. .А. & & & 1 & \\
\hline Cam1052 & $\ldots \mathrm{K} \ldots \ldots$ & $\ldots \ldots E \ldots \ldots$ & $\ldots \ldots \ldots \ldots \ldots \ldots \ldots$ & 1 & & & \\
\hline Cam1062 & $\ldots \ldots \ldots$ & $\ldots Q \ldots K \ldots R \cdot Q \ldots L$ & $\ldots \ldots \ldots \ldots \ldots$. & 2 & & 1 & \\
\hline Cam3006 & $\ldots \ldots \ldots$ & $\ldots Q \ldots K \ldots I \ldots L$ & $\ldots \ldots \ldots \ldots \ldots$. & 3 & 1 & & \\
\hline E08 & $\ldots \ldots \ldots$ & $\ldots \ldots \ldots$ T... & $\ldots \ldots \ldots \ldots \ldots \ldots$ & & 1 & & \\
\hline E12 & $\ldots \ldots \ldots$ & $\ldots Q \ldots K \ldots I \cdot Q \ldots L$ & $\ldots \ldots \ldots \ldots \ldots$. & 5 & 2 & 1 & \\
\hline G04 & $\ldots \ldots \ldots$ & $\ldots \ldots \mathrm{TE} \ldots . \mathrm{Q} \ldots \mathrm{L}$ & $\ldots \ldots \ldots$. G.S.N..... & & 1 & & \\
\hline G06 & $\ldots \ldots \ldots$ & $\ldots Q \ldots K \ldots Q \ldots Q \ldots L$ & $\ldots \ldots \ldots \ldots \ldots$. $\ldots$ A. & 1 & & & \\
\hline P-01 & $\ldots \ldots \ldots$ & $\ldots \ldots \ldots \ldots R \cdot Q \ldots L$ & $\ldots \ldots \ldots \ldots \ldots \ldots \ldots$ & 17 & & & 1 \\
\hline P-02 & $\ldots \ldots \ldots$ & $\ldots Q \ldots K \ldots N \ldots L$ & ............... & 3 & & & \\
\hline P-03 & $\ldots \ldots s$ & $\ldots \ldots K E \ldots N \ldots Q \ldots L$ & $\ldots \ldots \ldots \ldots \ldots \ldots \ldots$ & & & 3 & \\
\hline P-04 & $\ldots \ldots G \ldots$ & $\ldots Q \ldots K \ldots I \cdot Q \ldots L$ & $\ldots \ldots \ldots \ldots \ldots$. . А. & 2 & & & \\
\hline P-05 & $\ldots \ldots s$ & $\ldots \ldots K E \ldots N \ldots Q \ldots L$ & $\ldots \ldots \ldots \ldots$. .А. & 2 & & & \\
\hline P-06 & $\ldots \ldots \ldots$ & $\ldots \ldots \mathrm{KE} \ldots I \cdot Q \ldots \mathrm{L}$ & $\ldots \ldots \ldots$. & 2 & & & \\
\hline P-07 & $\ldots \ldots \ldots$ & $\ldots Q \ldots K \ldots Q \ldots Q \ldots L$ & $\ldots \ldots \ldots \ldots \ldots, \mathrm{Q} \ldots \ldots$ & 2 & & & \\
\hline P-08 & $\ldots \ldots \ldots$ & $\ldots Q \ldots K \ldots T \cdot Q \ldots L$ & $\ldots \ldots \ldots \ldots \ldots \ldots$ & 1 & & & \\
\hline P-09 & $\ldots \ldots \ldots$ & $\ldots \ldots K \ldots . . . \mathrm{L}$ & $\ldots \ldots \ldots \ldots \ldots \ldots$ A. & 1 & & & \\
\hline P-10 & $\ldots \ldots s$ & $\ldots \ldots K E \ldots N \ldots Q \ldots L$ & $\ldots$ G. . . . . . . . & 1 & & & \\
\hline P-11 & $\ldots \ldots \ldots$ & $\ldots \ldots E \ldots R \cdot Q \ldots L$ & $\ldots \ldots \ldots \ldots \ldots \ldots \ldots$ & 1 & & & \\
\hline P-12 & $\ldots \ldots \ldots$ & $\ldots Q \ldots K \ldots \mathrm{T} \ldots \mathrm{L}$ & 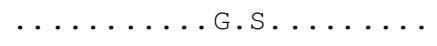 & & 1 & & \\
\hline P-13 & $\ldots \ldots \ldots$ & $\ldots Q \ldots K \ldots Q \ldots L L$ & $\ldots \ldots \ldots \ldots \ldots$. N $\ldots$ & 1 & & & \\
\hline P-14 & $\ldots \ldots \ldots$ & $\ldots \ldots \ldots$ T. & $\ldots \ldots \ldots \ldots \ldots \ldots$ & 1 & & & \\
\hline P-15 & $\ldots \ldots \ldots$ & $\ldots Q \ldots K \ldots \ldots$ & $\ldots \ldots \ldots \ldots \ldots \ldots$ & & 1 & & \\
\hline P-16 & $\ldots \ldots s$ & $\ldots \ldots$....N. . . L & $\ldots \ldots \ldots \ldots \ldots \ldots \ldots$ & 1 & & & \\
\hline P-17 & $\ldots \ldots s$ & $\ldots \ldots \mathrm{KE} \ldots \mathrm{N} \ldots \mathrm{Q} \ldots \mathrm{L}$ & $\ldots \ldots \ldots \ldots \ldots \ldots \ldots$ & 1 & & & \\
\hline P-18 & $\ldots \ldots \ldots$ & $\ldots Q \ldots K \ldots N \ldots \ldots$ & $\ldots \ldots \ldots \ldots \ldots$. & & & 1 & \\
\hline P-19 & $\ldots \ldots \ldots$ & $\ldots Q \ldots K \ldots R \cdot Q \ldots L$ & $\ldots \ldots \ldots \ldots \ldots \ldots \ldots$ & & 1 & & \\
\hline P-20 & $\ldots \ldots \ldots$ & $\ldots Q \ldots K \ldots Q I \cdot Q \ldots L$ & $\ldots \ldots \ldots \ldots \ldots$. . А. & & 1 & & \\
\hline $\mathrm{P}-21$ & $\ldots \ldots s$ & $\ldots$...KE . N . R. . L & $\ldots \ldots \ldots \ldots \ldots \ldots$ А. & 1 & & & \\
\hline P-22 & $\ldots \ldots s$ & $\ldots$. R.KE . N . Q. L L & $\ldots \ldots \ldots \ldots \ldots \ldots \ldots$ & 1 & & & \\
\hline $\mathrm{P}-23$ & $\ldots \ldots \ldots$ & $\ldots \ldots \mathrm{KE} \ldots \mathrm{N} \ldots \mathrm{Q} \ldots \mathrm{L}$ & $\ldots \ldots \ldots \ldots \ldots \ldots$ А. & 1 & & & \\
\hline P-24 & $\ldots \ldots \ldots$ & $\ldots \ldots K \ldots R \cdot Q \ldots L$ & $\ldots \ldots \ldots \ldots \ldots \ldots \ldots$ & 1 & & & \\
\hline P-25 & $\ldots \ldots \ldots$ & $\ldots Q \ldots E \ldots R \cdot Q \ldots L$ & $\ldots \ldots \ldots \ldots \ldots$. . A. & 1 & & & \\
\hline P-26 & $\ldots \ldots \ldots$ & $\ldots \ldots N K \ldots R \cdot Q \ldots L$ & $\ldots \ldots \ldots \ldots \ldots \ldots \ldots$ & 1 & & & \\
\hline P-27 & $\ldots \ldots \ldots$ & $\ldots Q \ldots E \ldots N \ldots Q \ldots$ & $\ldots \ldots \ldots \ldots \ldots \ldots \ldots$ & 1 & & & \\
\hline P-28 & $\ldots \ldots \ldots$ & $\ldots Q \ldots \mathrm{E} \ldots \mathrm{Q} \ldots$ & $\ldots \ldots \ldots \ldots \ldots \ldots \ldots$ & 1 & & & \\
\hline P-29 & $\ldots \ldots \ldots$ & $\ldots \ldots \ldots \ldots$ I.R.L & $\ldots \ldots \ldots$. . . Q. A. & 1 & & & \\
\hline P-30 & $\ldots \ldots \ldots$ & $\ldots \ldots \ldots \ldots T \cdot Q \ldots \mathrm{L}$ & $\ldots \ldots \ldots \ldots \ldots \ldots$ А. & 1 & & & \\
\hline Total & & & & 78 & 12 & 9 & \\
\hline
\end{tabular}

\section{Figure I}

Sequences of $P$. falciparum csp haplotypes found among field isolates from two hospitals (PCMH and M-34) in Freetown, Sierra Leone, during September-October 2006 and April-May 2007. Note that only variable sites immediately after the central repeats (labeled X i.e. amino residues $308-317$ ), and the regions spanning the Th2R (amino residues $326-342$ ) and Th3R (amino residues $356-378$ ) in the C-terminal portion of the gene are shown. Amino residue numbering is with reference to the 7G8 sequence and haplotypes labeled P-0I $\sim$ P-30 are unique to this study. The P-I7 haplotype differs from the 3D7 sequence by two silent nucleotide mutations but otherwise has an identical amino acid sequence. As shown, the "Asia-type*" refers to the Th2R*5/Th3R*I haplotype previously shown to be predominant in Asia, but was not detected in this study. 


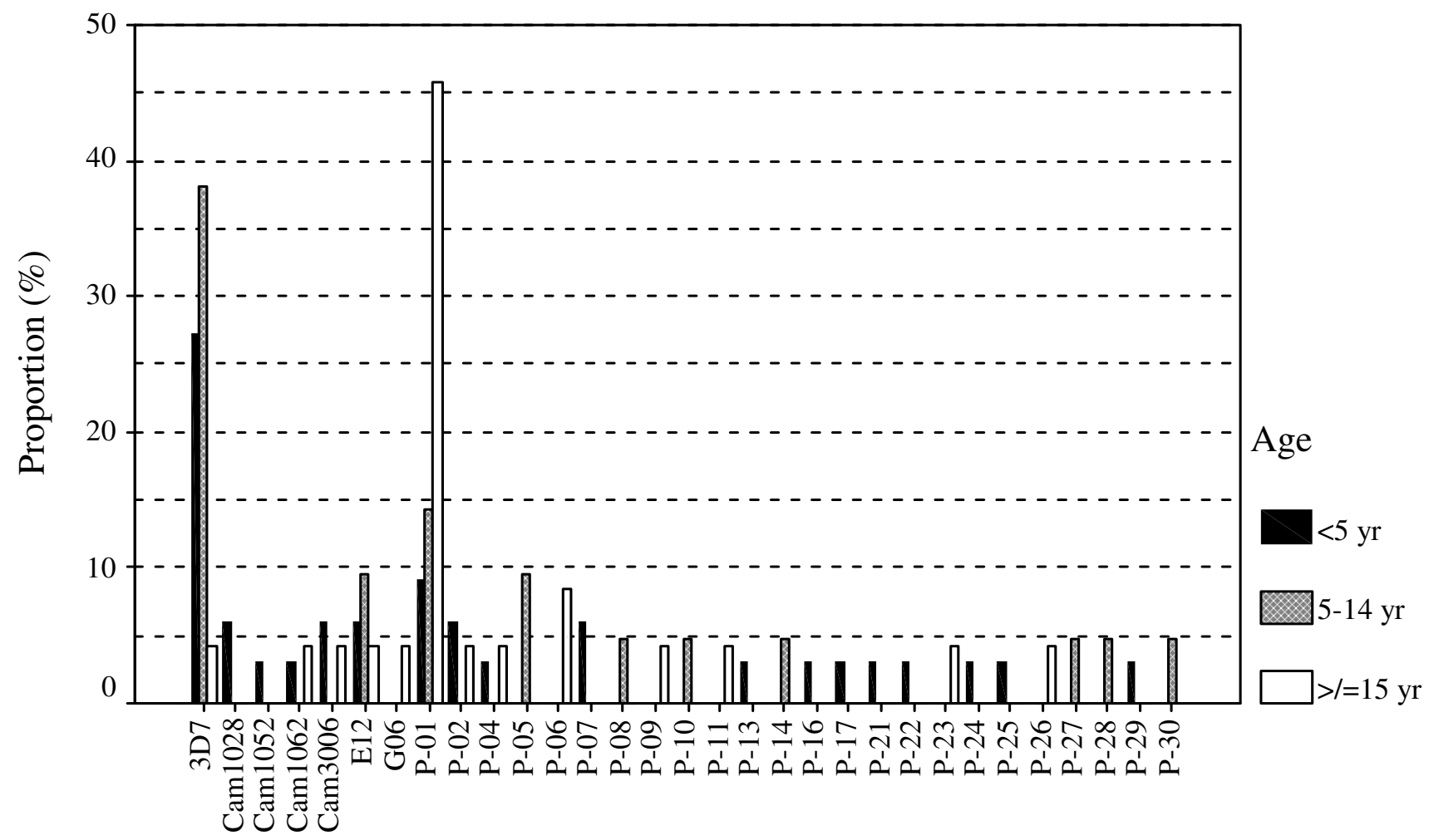

Haplotype ( $\mathrm{n}=78$ sequences $)$

Figure 2

Distribution of csp haplotypes by age category among the PCMH 2006 sequences for which $n=33,21$, and 24 for the 3 respective age groups: (i) less than 5 years (black bars) of age (ii) between 5 and I 4 years (grey bars) and (iii) I5 years or older (open bars). Note that all sequences from single-clone as well as the six double-clone infections were used in this analysis. The 3D7 haplotype was found more in children aged less than I5 years while the P-0I allele was more prevalent in adult females, who were mostly antenatal follow-up subjects.

the 7G8 sequence was found in all three countries except Vietnam. While this differential csp-haplotype distribution was statistically significant by Chi-square analysis using SPSS (Pearson Chi-square $=766.847$, d.f. $=219, P<$ $0.00001)$, it is of interest to note that not finding a particular haplotype does not completely preclude its existence in the locality of interest but may simply suggest it might be of low frequency. Another striking feature was that all mutations were almost always restricted to the same positions in the T-cell epitope regions of the gene, regardless of parasite origin. What seemed important was the nature of the substituting amino acid, again suggesting strong functional constraints on the CSP molecule.

As depicted in Table 2, within-population genetic diversity estimates ( $\pi$, haplotype diversity) reveal consistent patterns in all countries, with the Th2R epitope region being more polymorphic than the Th3R region. However, between-population genetic differentiation parameters
$\left(\mathrm{F}_{\mathrm{ST}}, \mathrm{Dxy}, \mathrm{Kxy}\right.$ and $\left.\mathrm{Da}\right)$ indicate regional differences, with African parasites having similar indices than they are to Asian parasites. This data is probably reminiscent of differences in transmission intensities/dynamics between the respective geographic regions.

\section{Discussion}

Presented here is the first malaria molecular epidemiologic study in Sierra Leone on the genetic diversity of T-cell epitope regions in the C-terminal portion of the P. falciparum circumsporozoite protein among wild isolates circulating in the capital, Freetown. Contrary to previous data presented from moderate to low endemic settings of malaria $[6-8,15]$, results of this study indicate that sequence polymorphisms in the same region of Pfcsp (Th2R/Th3R epitopes) in an African setting are markedly diverse, but again with some degree of restriction. In addition, the single-haplotype predominance of the "Asia type" sequence (proportion > 50\%) previously docu- 
Table 2: Intra-population genetic diversity and inter-population genetic differentiation estimates of Asian and African parasites

\begin{tabular}{|c|c|c|c|c|c|c|}
\hline \multicolumn{7}{|c|}{ (a) Intra-population genetic diversity parameters ${ }^{a}$} \\
\hline \multirow[b]{2}{*}{ Population } & \multirow{2}{*}{$\begin{array}{l}\text { No. of } \\
\text { sequences }\end{array}$} & \multirow{2}{*}{$\begin{array}{l}\text { No. of } \\
\text { haplotypes }\end{array}$} & \multirow{2}{*}{$\begin{array}{l}\text { Haplotype } \\
\text { diversity }\end{array}$} & \multicolumn{3}{|c|}{ Nucleotide diversity per site $(\pi)$} \\
\hline & & & & Th2R & Th3R & All sites \\
\hline Gambia & 44 & 21 & 0.95137 & 0.07526 & 0.04343 & 0.02882 \\
\hline Sierra Leone & 99 & 40 & 0.91899 & 0.06753 & 0.02926 & 0.02366 \\
\hline Vietnam & 142 & 20 & 0.69693 & 0.02625 & 0.01420 & 0.00983 \\
\hline Iran & 90 & 5 & 0.60275 & 0.01530 & 0.00632 & 0.00530 \\
\hline \multicolumn{7}{|c|}{ (b) Inter-population genetic differentiation parameters } \\
\hline Population-I & Population-2 & & $\mathrm{F}_{\mathrm{ST}}^{\mathrm{b}}$ & Dxyc & $\mathrm{Da}^{\mathrm{d}}$ & Kxye \\
\hline Gambia & Sierra Leone & & 0.04403 & 0.02745 & 0.00121 & 5.68205 \\
\hline Gambia & Vietnam & & 0.24410 & 0.02557 & 0.00624 & 5.29209 \\
\hline Gambia & Iran & & 0.27967 & 0.02366 & 0.00662 & 4.89798 \\
\hline Sierra Leone & Vietnam & & 0.31434 & 0.02442 & 0.00768 & 5.05499 \\
\hline Sierra Leone & Iran & & 0.37256 & 0.02305 & 0.00859 & 4.77149 \\
\hline Vietnam & Iran & & 0.13221 & 0.00870 & 0.00115 & 1.80031 \\
\hline
\end{tabular}

aEstimates are based on pair wise analyses of 375 sequences of the C-terminal portion (207 bp) of the CSP gene spanning the Th2R and Th3R using DnaSP4.5 (2I)

bFST: Wright's Fixation index, which is a measure of genetic differentiation between populations (range from 0 to +1 )

cDxy: measures the average number of nucleotide differences per site between populations

${ }^{\mathrm{d}} \mathrm{Da}$ : measures the number of net nucleotide substitutions per site between populations

eKxy: measures the average proportions of nucleotide substitutions per site between populations

mented in Asia (Additional file 1) was not observed in this African setting. Instead three haplotypes accounted for the majority (44.4\%) of the sequences i.e. 3D7 (19.2\%), P-01 $(17.2 \%)$ and $\mathrm{E} 12(8.1 \%)$, and with intriguing distribution patterns. The 3D7 allele was associated with hospitalized children in two age groups ( $<5$ years of age and $5-15$ years of age), but not with adults, while another previously undescribed haplotype (P-01) was significantly associated with visiting antenatal subjects $(P=0.049)$. Since most of these antenatal females were of mild or asymptomatic infection, this finding inevitably warrants the speculation whether distribution of $P$. falciparum csp haplotypes could be associated with disease severity i.e. does naturallyacquired immunity select for certain CSP variants in malaria-endemic areas? While the data presented here may in part support this notion, it may also be argued that this study may have suffered due to limited sample size (thus underpowered), or the findings may have been simply due to chance (borderline $P$ values). Whatever the case, this haplotype distribution pattern in an African endemic area is important in that it adds insight into a relevant issue in vaccine design and evaluation i.e. could there indeed be significant differences of vaccine effects in symptomatic versus asymptomatic malaria individuals, particularly in the context of an African endemic setting where transmission is usually intense? This might be a major issue for consideration in future large-scale longitudinal studies on malaria antigen polymorphisms of vaccine antigens in other endemic nations.
Despite the documented polymorphisms in CSP, the mechanism(s) behind them are poorly understood. Proposed mechanisms include intragenic recombination and natural selection (human immune pressure- or mosquitoinduced). In recent field trials of the most advanced CSP vaccine (RTS,S), it was demonstrated that vaccine-mediated immunity was not strain-specific [21], nor did the vaccine induce T-cell epitope selection [12]. A subsequent study using samples from Thailand further questioned the contribution of human immune pressure towards epitope diversity in the $\operatorname{csp}$ [8]. Thus it was suggested that this scenario could be due to a major contributory role of "mosquito-induced" selection by the different vector species transmitting malaria in the different geographic regions $[8,15]$. However, it appears that this "mosquito-induced" selection may not completely explain the observed differential haplotype distribution patterns in different endemic settings, as documented in this study. Moreover, although one study recently demonstrated that sterile protection is independent of the circumsporozoite protein [22], the role of the human immune system is supported by other studies documenting induced immune responses to CSP [23-26]. Taken together, the data suggest that the role of the human host's immune pressure cannot be completely excluded, even if it potentially leads to a nonprotective or partially protective immune response, as might be expected in an immune-evasion strategy.

Thus, a more likely explanation would incorporate a complex interplay of a combination of factors including hostimmune selection (presumably due to differential bind- 
ing of parasite-derived peptides to host molecules), transmission dynamics, strong functional constraints on the protein, as well as the reproductive nature of the parasite. Which factor(s) contribute a major role at any given time and place would depend largely on a "net effect" given the local epidemiologic situation. Generally, regions of high $P$. falciparum transmission intensity correlate with high parasite prevalence and high genetic diversity of the parasite, with resultant high proportion of mixed genotypes in a given infection. This would increase the probability that a feeding mosquito obtains genetically distinct haplotypes in its blood meal, which in turn increases the probability of out-crossing in the midgut. This is consistent with data presented here considering the numerous CSP haplotypes circulating in this African endemic setting, as well as the tendency for sympatric parasites appearing to be more closely related than their allopatric counterparts (Figure 1, Table 2). In low transmission areas, it is expected that the low genetic diversity would limit the observed recombination events as detected by common algorithms, with the tendency of having a somewhat "clonal" population pattern in such low transmission areas. The finding of a predominant haplotype using larger samples in Asia e.g. the "Asia-type" (Additional file 1) and, more recently, the predominance of the 7G8 haplotype in Peru [27] would support this scenario. In short, it may be necessary to reflect these epidemiologic differences while interpreting field data on $c s p$ or other malaria antigen polymorphisms.

Hopefully future large-scale studies on Pfcsp polymorphism, supplemented with well-coordinated entomologic and sero-immunological analyses, in other African endemic areas would shed more light on this issue, similar to what was recently documented for the $P$. falciparum merozoite surface protein-1 (MSP-1) in Mali [28].

\section{Conclusion}

This study highlights an apparent discordant haplotype distribution of the T-cell epitopes of Pf-CSP with respect to age. In addition, the observed sequence polymorphism patterns were similar to that in neighbouring Gambia, but differed significantly at the sequence level from that observed in Asia. Thus, the interpretation of genetic diversity data of malaria antigen genes should probably reflect not only the antigen but also the local epidemiologic situation. In the context of the RTS,S vaccine, its future deployment in Sierra Leone is envisioned to confer similar protection in children based on extrapolation of efficacy results from The Gambia and Mozambique, because the 3D7 haplotype appears to be prevalent in this endemic setting.

\section{Competing interests}

The authors declare that they have no competing interests.

\section{Authors' contributions}

AJ, MJ and HM participated in the field and molecular genetic studies, AJ performed the sequence alignment and drafted the manuscript. HM and AJ conceived of the study, and participated in its design and coordination. All authors read and approved the final manuscript.

\section{Additional material}

\section{Additional file 1 \\ Summary of C-terminal sequences of $P$. falciparum circumsporozoite protein of field isolates $(\mathrm{N}=375)$ from Asia and Africa. The data pre- sented represents a comparison of haplotype $(H)$ proportions of sequences of $\mathrm{P}$. falciparum csp of field isolates collected from different countries in Asia and Africa. Only the region of the gene spanning the Th2R and Th3R was used (i.e. amino acid positions $326-394$, with reference to the sequence of the 7G8 strain). \\ Click here for file \\ [http://www.biomedcentral.com/content/supplementary/1475- 2875-8-120-S1.xls]}

\section{Acknowledgements}

The authors are greatly indebted to the patients and guardians who volunteered for this study and to the following for their assistance during fieldwork: I. Gamanga, A. Kamara, M. Kamara and all staff of the PCMH

Microbiology Laboratory in Freetown, and Drs. D. Baion, A. Mustapha, and A. Tejan, for their helpful support. We thank Drs. S. Foday and P. Nabieu for assistance with sample collection as well as staff at the Thirty-Fourth Military Hospital (Wilberforce). Y. Kasahara (Japan) is also acknowledged for technical support during genotyping. Professor K. Tanabe (Osaka University, Japan) and M.U. Ferreira (University of Sao Paolo, Brazil) are greatly appreciated for their critical comments. This study was funded by a Postdoctoral Fellowship for Foreign Researchers to AJ (18-0646I) and a grantin-aid to HM (I 7406025) from The Japan Society for the Promotion of Science (JSPS).

\section{References}

I. Breman JG, Alilio MS, Mills A: Conquering the intolerable burden of malaria: what's new, what's needed: a summary. $\mathrm{Am} J$ Trop Med Hyg 2004, 71: I-I5.

2. Gordon DM, McGovern TW, Krzych U, Cohen JC, Schneider I, LaChance R, Heppner DG, Yuan G, Hollingdale M, Slaoui M, Hauser P, Voet P, Sadoff JC, Ballou WR: Safety, immunogenicity, and efficacy of a recombinantly produced Plasmodium falciparum circumsporozoite protein-hepatitis B surface antigen subunit vaccine. J Infect Dis 1995, I7 I:I576-1585.

3. Bojang KA, Milligan PJ, Pinder M, Vigneron L, Alloueche A, Kester KE, Ballou WR, Conway DJ, Reece WH, Gothard P, Yamuah L, Delchambre M, Voss G, Greenwood BM, Hill A, McAdam KP, Tornieporth N, Cohen JD, Doherty T: Efficacy of RTS,S/ASO2 malaria vaccine against Plasmodium falciparum infection in semi-immune adult men in The Gambia: a randomised trial. Lancet 200I, 358:1927-1934

4. Alonso PL, Sacarlal J, Aponte JJ, Leach A, Macete E, Milman J, Mandomando I, Spiessens B, Guinovart C, Espasa M, Bassat Q, Aide P, OforiAnyinam O, Navia MM, Corachan S, Ceuppens M, Dubois MC, Demoitie MA, Dubovsky F, Menendez C, Tornieporth N, Ballou WR, Thompson R, Cohen J: Efficacy of the RTS,S/AS02A vaccine against Plasmodium falciparum infection and disease in young African children: randomised controlled trial. Lancet 2004, 364: $14 \mid 1-1420$

5. Bojang KA: RTS,S/AS02A for malaria. Expert Rev Vaccines 2006, 5:6||-6|5. 
6. Tanabe K, Sakihama N, Kaneko A: Stable SNPs in malaria antigen genes in isolated populations. Science 2004, 303:493.

7. Jalloh A, van Thien H, Ferreira MU, Ohashi J, Matsuoka H, Kanbe T, Kikuchi A, Kawamoto F: Sequence variation in the T-cell epitopes of the Plasmodium falciparum circumsporozoite protein among field isolates is temporally stable: a 5-year longitudinal study in southern Vietnam. J Clin Microbiol 2006, 44:1229-1235.

8. Kumkhaek C, Phra-Ek K, Renia L, Singhasivanon P, Looareesuwan S, Hirunpetcharat C, White NJ, Brockman A, Gruner AC, Lebrun N, Alloueche A, Nosten F, Khusmith S, Snounou G: Are extensive T cell epitope polymorphisms in the Plasmodium falciparum circumsporozoite antigen, a leading sporozoite vaccine candidate, selected by immune pressure? J Immunol 2005, 175:3935-3939.

9. Jalloh A, Jalloh M, Gamanga I, Baion D, Sahr F, Gbakima A, Willoughby VR, Matsuoka H: G6PD deficiency assessment in Freetown, Sierra Leone, reveals further insight into the molecular heterogeneity of G6PD A-. J Hum Genet 2008, 53:675-679.

10. Bockarie MJ, Gbakima AA, Barnish G: It all began with Ronald Ross: 100 years of malaria research and control in Sierra Leone (1899-1 999). Ann Trop Med Parasitol 1999, 93:2 I3-224.

11. Checchi F, Roddy P, Kamara S, Williams A, Morineau G, Wurie AR, Hora B, Lamotte N, Baerwaldt T, Heinzelmann A, Danks A, Pinoges L, Oloo A, Durand R, Ranford-Cartwright L, Smet M: Evidence basis for antimalarial policy change in Sierra Leone: five in vivo efficacy studies of chloroquine, sulphadoxine-pyrimethamine and amodiaquine. Trop Med Int Health 2005, I0:146-I 53.

12. Enosse S, Dobano C, Quelhas D, Aponte J], Lievens M, Leach A, Sacarlal J, Greenwood B, Milman J, Dubovsky F, Cohen J, Thompson R, Ballou WR, Alonso PL, Conway DJ, Sutherland CI: RTS,S/AS02A malaria vaccine does not induce parasite CSP T cell epitope selection and reduces multiplicity of infection. PLOS Clin Trials 2006, I:e5.

13. Tamura K, Dudley J, Nei M, Kumar S: MEGA4: Molecular Evolutionary Genetics Analysis (MEGA) software version 4.0. Mol Biol Evol 2007, 24:1596-I599.

14. Dame JB, Williams JL, McCutchan TF, Weber JL, Wirtz RA, Hockmeyer WT, Maloy WL, Haynes JD, Schneider I, Roberts D, et al. Structure of the gene encoding the immunodominant surface antigen on the sporozoite of the human malaria parasite Plasmodium falciparum. Science 1984, 225:593-599.

15. Zakeri S, Avazalipoor M, Mehrizi AA, Djadid ND, Snounou G: Restricted T-cell epitope diversity in the circumsporozoite protein from Plasmodium falciparum populations prevalent in Iran. Am J Trop Med Hyg 2007, 76: I046-105I.

16. Weedall GD, Preston BM, Thomas AW, Sutherland CJ, Conway DJ: Differential evidence of natural selection on two leading sporozoite stage malaria vaccine candidate antigens. Int J Parasitol 2007, 37:77-85.

17. Rozas J, Sanchez-DelBarrio JC, Messeguer X, Rozas R: DnaSP, DNA polymorphism analyses by the coalescent and other methods. Bioinformatics 2003, 19:2496-2497.

18. Nei M: Molecular Evolutionary Genetics. New York: Columbia University Press; 1987.

19. Wright S: The genetical structure of populations. Ann Eugenics 1951, I 5:323-354

20. Frevert U, Sinnis P, Cerami C, Shreffler W, Takacs B, Nussenzweig V: Malaria circumsporozoite protein binds to heparan sulfate proteoglycans associated with the surface membrane of hepatocytes. J Exp Med 1993, 177:1287-। 298.

21. Alloueche A, Milligan P, Conway DJ, Pinder M, Bojang K, Doherty T, Tornieporth N, Cohen J, Greenwood BM: Protective efficacy of the RTS,S/ASO2 Plasmodium falciparum malaria vaccine is not strain specific. Am J Trop Med Hyg 2003, 68:97-I0I.

22. Gruner AC, Mauduit M, Tewari R, Romero JF, Depinay N, Kayibanda M, Lallemand E, Chavatte JM, Crisanti A, Sinnis P, Mazier D, Corradin G, Snounou G, Renia L: Sterile protection against malaria is independent of immune responses to the circumsporozoite protein. PLOS ONE 2007, 2:el37I.

23. Good MF, Pombo D, Quakyi IA, Riley EM, Houghten RA, Menon A, Alling DW, Berzofsky JA, Miller LH: Human T-cell recognition of the circumsporozoite protein of Plasmodium falciparum: immunodominant T-cell domains map to the polymorphic regions of the molecule. Proc Natl Acad Sci USA 1988, 85: $1199-1203$.
24. Sun P, Schwenk R, White K, Stoute JA, Cohen J, Ballou WR, Voss G, Kester KE, Heppner DG, Krzych U: Protective immunity induced with malaria vaccine, RTS,S, is linked to Plasmodium falciparum circumsporozoite protein-specific CD4+ and CD8+ T cells producing IFN-gamma. J Immunol 2003, | 1 1:696|-6967.

25. Kumar KA, Sano G, Boscardin S, Nussenzweig RS, Nussenzweig MC Zavala $F$, Nussenzweig $V$ : The circumsporozoite protein is an immunodominant protective antigen in irradiated sporozoites. Nature 2006, 444:937-940.

26. Pinder $M$, Reece $W H$, Plebanski M, Akinwunmi P, Flanagan KL, Lee EA, Doherty T, Milligan P, Jaye A, Tornieporth N, Ballou R, McAdam $\mathrm{KP}$, Cohen J, Hill AV: Cellular immunity induced by the recombinant Plasmodium falciparum malaria vaccine, RTS,S/AS02, in semi-immune adults in The Gambia. Clin Exp Immunol 2004, 135:286-293.

27. Chenet SM, Branch OH, Escalante AA, Lucas CM, Bacon DJ: Genetic diversity of vaccine candidate antigens in Plasmodium falciparum isolates from the Amazon basin of Peru. Malar J 2008, 7:93.

28. Takala SL, Coulibaly D, Thera MA, Dicko A, Smith DL, Guindo AB, Kone AK, Traore K, Ouattara A, Djimde AA, Sehdev PS, Lyke KE, Diallo DA, Doumbo OK, Plowe CV: Dynamics of polymorphism in a malaria vaccine antigen at a vaccine-testing site in Mali. PLoS Med 2007, 4:e93.

Publish with Bio Med Central and every scientist can read your work free of charge

"BioMed Central will be the most significant development for disseminating the results of biomedical research in our lifetime. "

Sir Paul Nurse, Cancer Research UK

Your research papers will be:

- available free of charge to the entire biomedical community

- peer reviewed and published immediately upon acceptance

- cited in PubMed and archived on PubMed Central

- yours - you keep the copyright 